\title{
Enrichment of U, Mo, V, Ni and Ti from asphaltite ash
}

\author{
Işıl Aydın, Furat Aydın, Recep Ziyadanoğullart* \\ Dicle University, Science and Arts Faculty, \\ Chemistry Department, 21180, Diyarbakir, TURKEY
}

\begin{abstract}
:
In this study, the ash was sulfurized in an autoclave before flotation. The sulfurization process was conducted at different amounts of $\mathrm{H}_{2} \mathrm{~S}$ and $\mathrm{H}_{2} \mathrm{O}$ steam. The flotation process was continued with the obtained samples. By flotation of the sample obtained from optimum sulfurization conditions, the concentrates containing all the uranium, molybdenum, vanadium, nickel and titanium was obtained. It was established that the above mentioned elements were enriched 12 times more than the original ash at the concentrate phase. The original ash was tried to enriched by flotation. However, the results obtained from this study was not encouraging. Therefore, ash was sulfurized in autoclave before flotation. In the flotation studies $\mathrm{K}$-isobutylxanthate and $\mathrm{K}$ amylxanthate were used as the collectors and the Aeroflat 65 was used as the frother.
\end{abstract}

Keywords: Flotation, molybdenum, uranium, vanadium, asphaltite ash.

* For correspondance :

Fax: $+90-412-2488039$

Tel : +90-412-2488001/3159

E-mail: recepz@dicle.edu.tr

\section{INTRODUCTION}

Flotation has permitted the mining of low grade complex ores, which would have been worthless if it had been necessary to rely on the time-honoured method of gravity concentration. In addition, tailing dumps of older mines can be reclaimed. In fact, the tailings of some previous gravity operations were higher grades than the ores being mined in many mines of today. To the mineral world, flotation has provided millions of tons of material that otherwise would not be economically available.

Early flotation efforts were directed primarily towards the recovery of copper, lead, and zinc, but other materials are now recovered from other metallic ores. The great and growing demand for molybdenum could not be satisfied without molybdenite, produced as a by product in copper production. Other metallics recovered by flotation include manganese, nickel, cobalt, vanadium, and bismuth [1].

In the flotation process, certain of the flotation reagents have been used for better separation. Flotation processing involves three main steps; (i) selective chemical modification of specific mineral surfaces to effect hydrophobicity/hydrophilicity 
(flotability or nonflotability), (ii) contact between and adherence of hydrophobic mineral particles to air bubbles, and (iii) separation of the flotable and nonflotable particles [2-5].

The Beaverlodge mill was used for flotation to remove pyrite from ground ore prior to carbonate leaching to avoid excessive reagent consumption. Frequent efforts to separate arsenic and nickel mineralization from uranium in Northern Saskatchewan ores, utilizing radiometric sorting, flotation, gravity separation and screening have been uniformly unsuccessful. These separation efforts failed because of the fine intergrowth between arsenic/nickel minerals [ for example, millerite (NiS), niccolite(NiAs) and gersdorffite (NiAsS) ] and uranium minerals such as uranite and coffinite [6].

The uranium ore from Jaduguda mine in India is one such deposit which needs to be looked into from this point of view. Apart from uranium, it also contains valuable minerals such as sulfide minerals of copper, molybdenum and nickel, as well as magnetite and apatite. Currently, some of the minerals such as copper and molybdenum are recovered and marketed as their concentrates. Magnetite is recovered from the ore after uranium extraction and sold to the nearby coal washeries for use as heavy medium. Part of the nickel sulfide minerals are recovered in the flotation stage, but not upgraded to meet the market specifications [7].

Asphaltite ashes contain different amounts of $\mathrm{U}, \mathrm{Mo}, \mathrm{V}, \mathrm{Ni}, \mathrm{Ti}$ and other transition metals depending on their formations. Main components of ash are quartz, calcite gypsum and metal oxides. The effect of parameters such as collectors, frothers, depressants, activators, particle size, pulp density, $\mathrm{pH}$ and temperature were investigated to enrich $\mathrm{U}, \mathrm{Mo}, \mathrm{V}, \mathrm{Ni}$ from asphaltite ashes and different minerals by flotation [8-13].

So far, it has been reported that enrichment methods performed by classical flotation have not produced the desired results. The authors applied these classical methods to similar samples and likewise, have not obtained good results. Therefore, the authors have developed a new method in which surface properties were changed to influence flotation.

To that end, asphaltite ash was reacted with $\mathrm{H}_{2} \mathrm{~S}(\mathrm{~g})$ under an autoclave, then the samples obtained (Sulfurized sample, SS) were floated for floatability of the mentioned elements. The main aim of this study was to determine to what extent the chemical reaction influences flotation yield.

\section{EXPERIMENTAL DESIGN}

\section{Material and Method}

Preparation of asphaltite ash: Asphaltite sample was supplied from Silopi (in the Southeastern Anatolia Region in Turkey ), ignited at atmospheric conditions, sieved to -100 mesh size, roasted at $900{ }^{\circ} \mathrm{C}$ for 4 hours and again siezed to -100 mesh size, dried at $110^{\circ} \mathrm{C}$, kept in bottles and used later. The chemical analyses of asphaltite ash are given in 
Table 1. Main components of ash not presented in Table 1 are calcide, silica and some metal oxides $\left(\mathrm{Fe}_{\mathrm{x}} \mathrm{O}_{\mathrm{y}}, \mathrm{Al}_{2} \mathrm{O}_{3}, \mathrm{MgO}\right)$ which form approximately $90 \%$ of ash.

Table 1- The chemical analysis of asphaltite ash*

\begin{tabular}{|l|c|c|c|c|c|c|c|}
\hline Compounds & $\mathbf{M o}$ & $\mathbf{N i}$ & $\mathbf{V}$ & $\mathbf{T i}$ & $\mathbf{A l}$ & $\mathbf{F e}$ & $\mathbf{U}_{\mathbf{3}} \mathbf{O}_{\mathbf{8}}$ \\
\hline Composition (\%) & 0,33 & 0,45 & 0,60 & 0,44 & 9,47 & 2,96 & 0,05 \\
\hline
\end{tabular}

Reagents: All the chemicals used were of analytical grade.

Apparatus: A flame atomic absorption spectrometer (UNICAM 929 Model AAS) and an atomic emission spectrophotometer (JOBIN YVON JY 24 Model ICP-AES ) were used for the determination of nickel and iron, and uranium, molybdenum, aluminum, titanium and vanadium concentrations in the solution, respectively. D12 flotation apparatus, Heraus Model Furnace and Nel 890 Model pH meter were used for flotation, roasting and determination of $\mathrm{pH}$ of samples, respectively.

\section{RESULTS AND DISCUSSION}

\section{Flotation of Original Ash}

The main aim of collective flotation is to remove Mo, V, Ni, U and Ti from the main components of the original sample. The first flotation process was conducted by the following conditions. The results are given in Table 2.

Table 2- Flotation of Orginal Ash*

\begin{tabular}{|c|c|c|c|c|c|c|c|}
\hline \multirow{2}{*}{$\begin{array}{c}\text { Flotation Time } \\
\text { (Minute) }\end{array}$} & \multicolumn{7}{|c|}{ Flotation yield of the elements (\%) } \\
\cline { 2 - 8 } & $\mathbf{M o}$ & $\mathbf{V}$ & $\mathbf{U}$ & $\mathbf{T i}$ & $\mathbf{A l}$ & $\mathbf{N i}$ & $\mathbf{F e}$ \\
\hline 40 & 2.85 & 2.48 & 2.21 & 1.77 & 1.70 & 2.20 & 2.10 \\
\hline Unfloated & 97.00 & 98.70 & 97.50 & 98.00 & 98.00 & 97.50 & 98.10 \\
\hline
\end{tabular}

Flotation conditions: Collector : potassium isobuthylxhantate $(0.2 \mathrm{~g} / \mathrm{L})$; Frother : Aeroflat $65(0.2 \mathrm{~mL}$, 1\%) ; $\mathrm{pH}: 6.5$; Particle dimension : -100 mesh ; Stirring rate : 900 rotation / min ; Time of flotation : 40 min. , solid/liquid $: 100 \mathrm{~g} / \mathrm{L}$

Table 2 shows that percent values of the flotation yield of the elements at 40 minutes and $21.98 \mathrm{~g}$ of floated was determined.

As seen in Table 2, none of the elements were collected in concentrated phase by direct flotation of the original sample. The next flotation process was not carried out by direct flotation of original ash.

\section{Sulfurization of Asphaltite ash in autoclave conditions:}


Firstly, samples of original ash were ground, sieved with 100 mesh, dried at 110 ${ }^{0} \mathrm{C}$ and then reacted at $100{ }^{\circ} \mathrm{C}$ with gas mixtures containing different amounts of $\mathrm{H}_{2} \mathrm{~S}+$ $\mathrm{H}_{2} \mathrm{O}$ for 1 hour. For this purpose, $500.00 \mathrm{~g}$ original ash samples were reacted separately with mixtures of $\mathrm{H}_{2} \mathrm{~S}$ and $\mathrm{H}_{2} \mathrm{O}$ to be investigated according to Table 3 .

The reason for choosing the Table 3 condition was to increase the flotation yield. This would result in a new surface and structure. The values for the sulfurization of Mo, $\mathrm{V}, \mathrm{U}, \mathrm{Fe}$ and $\mathrm{Ni}$ are given in Table 3. The amounts of floated and unfloated ash of sulfurized ash are given in Figure 1.

Table 3- The used amount of mixtures of $\mathrm{H}_{2} \mathrm{~S}$ and $\mathrm{H}_{2} \mathrm{O}$.

\begin{tabular}{|c|c|c|}
\hline Experimental No & Amount of $\mathrm{H}_{2} \mathrm{~S}(\mathrm{~g})$ & Amount of $\mathrm{H}_{2} \mathrm{O}(\mathrm{g})$ \\
\hline 1 & 1.09 & 5.0 \\
\hline 2 & 1.36 & 12.5 \\
\hline 3 & 1.64 & 12.5 \\
\hline 4 & 2.05 & 15.0 \\
\hline 5 & 2.18 & 16.0 \\
\hline 6 & 2.46 & 18.0 \\
\hline 7 & 2.73 & 20.0 \\
\hline
\end{tabular}

As seen in Figure 1, it was apparent that the lowest amount of material was floated for the seventh experiment condition. At the end of the process, the floated amount of $\mathrm{Mo}, \mathrm{V}, \mathrm{Ni}, \mathrm{U}, \mathrm{Al}, \mathrm{Fe}$ and $\mathrm{Ti}$ are given in Figure 2.

The samples were
floated under the same conditions as the original ash.

As seen in Figure 2, Mo,

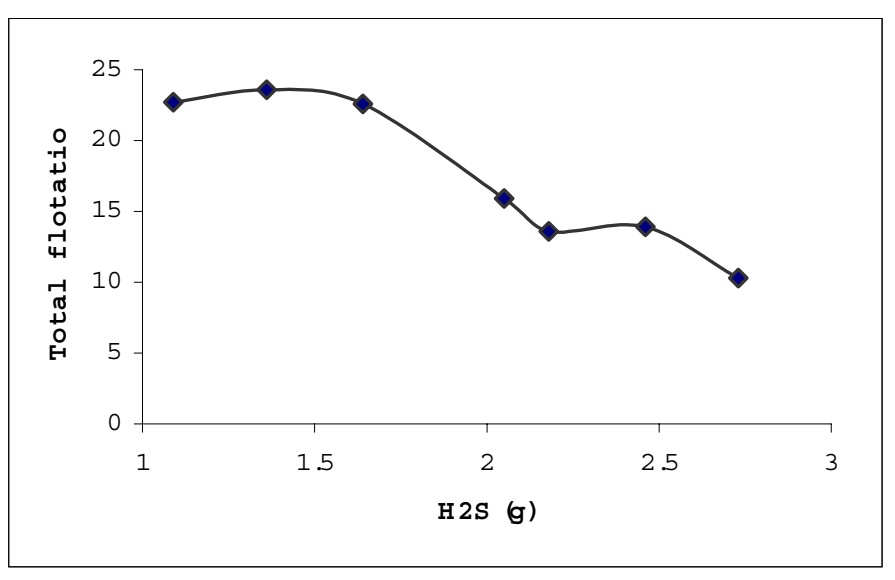

Fig. 1- Effect of $\mathrm{H}_{2} \mathrm{~S}$ on total flotation* $\mathrm{V}, \mathrm{U}, \mathrm{Ni}$, and $\mathrm{Ti}$ were floated with maximum yield in concentrated phase according to experiment 7 by flotation of sulfurized ash for 40 minutes.

In order to investigate the dimension of sample on the flotation yield, the sulfurized sample was ground, sieved $(-100,-200$ and -300 mesh) and floated the same conditions (experiment 7). The results are given in Figure 3.

In Figure 3, Mo, V, Ni, U and Ti values obtained from each sample were quite close to each other. It was determined that, while in the flotation of the sample with -100 mesh , $11.02 \mathrm{~g}$ was collected, in the flotation of -200 mesh, $8.03 \mathrm{~g}$ was collected and in 

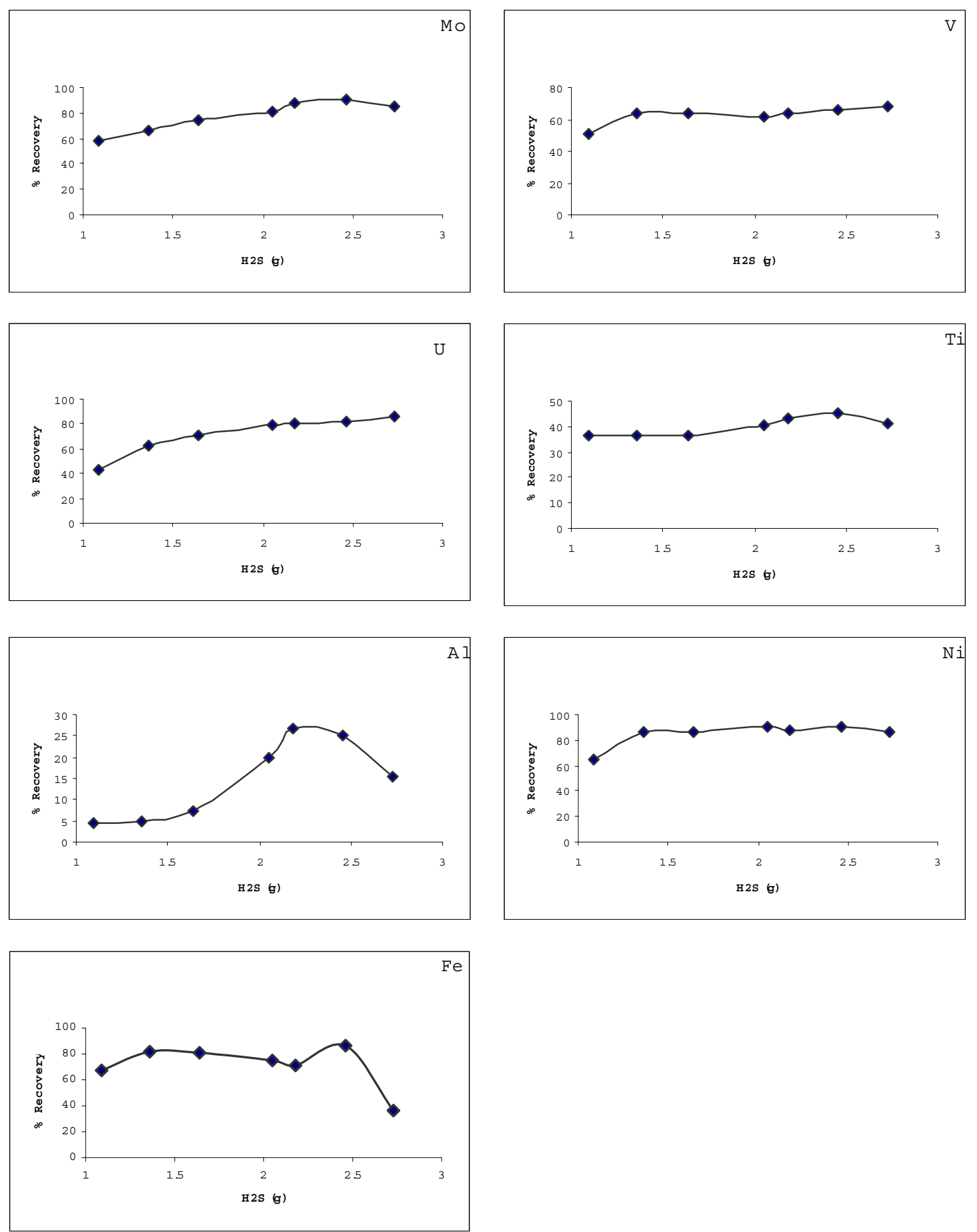

Fig. 2- Effect of $\mathrm{H}_{2} \mathrm{~S}$ on flotation of sulfurized asphaltite ash*.

the flotation of -300 mesh sample, $17.81 \mathrm{~g}$ was collected in concentrated phase. It was found that yields in both flotations were closer. Especially, the percentages of Mo, V, Ni, $\mathrm{U}$ and $\mathrm{Ti}$ in the sample were determined to be approximately two times greater than with -300 mesh. It was concluded that flotation of -200 mesh particle size was suitable. 
The effect of $\mathrm{pH}$ on flotation was also studied. Equilibrium $\mathrm{pH}$ were adjusted as 6.2, 6.5, 7.0, 7.5, 8.0 and 8.5, respectively. Experiments were performed by using sulfurized -200 mesh samples, and flotation was carried on for 40 minutes. During this time, since substance was not transported to foam, the process was stopped. Flotation yields obtained and amount of substances are shown in Figure 4.

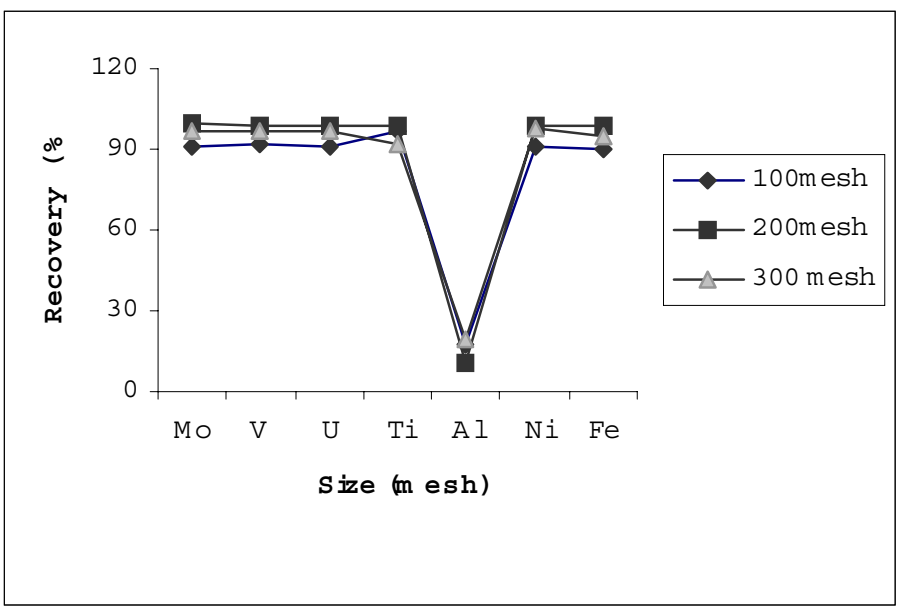

Fig. 3-Effect of size on the flotation at sulfurized samples*

As seen

in Figure 4, the maximum

flotation yield was reached at $\mathrm{pH}$ 6.5. Yields of Al was lowest at this $\mathrm{pH}$, consistent with what would be expected. The transported matter at this $\mathrm{pH}$ to concentrated phase was the lowest, as $8.71 \mathrm{~g}$

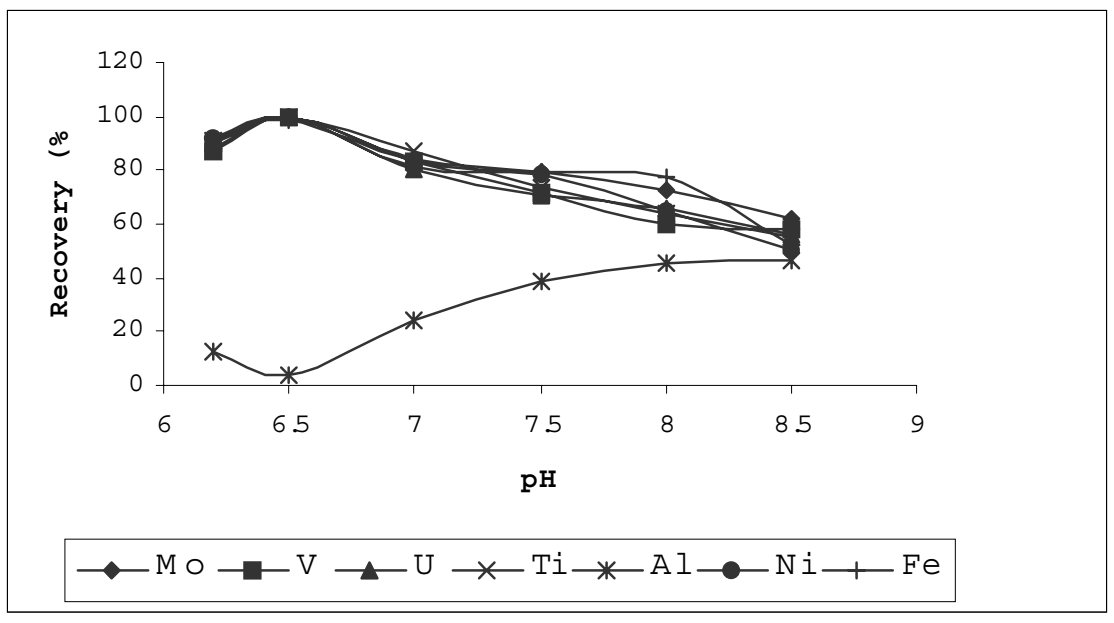

Fig. 4- The Effect of pH on the Floatability of Sulfurized Samples* *: Averages calculated for data obtained from three independent flotation experiments as seen in Figure

4. Therefore, the $\mathrm{pH}$ dependent studies were carried out at above $\mathrm{pH}: 6,5$. In the below $\mathrm{pH}: 6,5$, the $\mathrm{H}_{2} \mathrm{~S}$ gas was produced and the flotation yield was decreased. Therefore, the results obtained from this $\mathrm{pH}$ was not given. In the present study, harm to the environment was avoided.

By keeping of experimental conditions constant in the seventh experiment, flotation processes were conducted by changing pulp density. For this purpose, $150.0 \mathrm{~g}$, $200.0 \mathrm{~g}, 250.0 \mathrm{~g}, 300.0 \mathrm{~g}$ of samples were put in $1000 \mathrm{~mL}$ of solution experiments which were repeated twice for each. Experimental results are given in Table 4 and Table 5. 
Table 4- The effect of pulp density on the floatability of the elements*.

\begin{tabular}{|c|c|c|c|c|c|c|c|c|}
\hline Sample & Floated amount & \multicolumn{8}{|c|}{ Floatability of elements (\%) } \\
\cline { 3 - 9 } & $\mathbf{( g )}$ & $\mathbf{M o}$ & $\mathbf{V}$ & $\mathbf{U}$ & $\mathbf{T i}$ & $\mathbf{A l}$ & $\mathbf{N i}$ & $\mathbf{F e}$ \\
\hline 150.0 & 14,22 & 100.0 & 100.0 & 100.0 & 100.0 & 7.1 & 99.8 & 99.1 \\
\hline 200.0 & 17,75 & 100.0 & 100.0 & 100.0 & 100.0 & 8.4 & 100.0 & 99.9 \\
\hline 250.0 & 24,96 & 99.0 & 100.0 & 100.0 & 99.0 & 8.9 & 100.0 & 99.5 \\
\hline 300.0 & 30,35 & 99.0 & 99.0 & 99.0 & 99.0 & 9.6 & 99.7 & 99.0 \\
\hline 350.0 & 36,03 & 99.0 & 99.0 & 99.0 & 99.0 & 9.9 & 99.4 & 98.8 \\
\hline
\end{tabular}

Flotation time is 40 minutes.

Table 5- Percentages of matter in concentrated phase by flotation of Sample 7*.

\begin{tabular}{|c|c|c|}
\hline Elements & $\begin{array}{c}\text { The elements in the } \\
\text { concentrate (\%) }\end{array}$ & Enrichment ratio \\
\hline $\mathrm{Mo}$ & 3.73 & 11.30 \\
\hline $\mathrm{V}$ & 6.90 & 11.50 \\
\hline $\mathrm{Ni}$ & 5.42 & 12.04 \\
\hline $\mathrm{Ti}$ & 5.21 & 11.84 \\
\hline $\mathrm{U}_{3} \mathrm{O}_{8}$ & 0.62 & 12.40 \\
\hline $\mathrm{Fe}$ & 31.95 & 10.79 \\
\hline $\mathrm{Al}$ & 9.74 & 1.10 \\
\hline
\end{tabular}

In Table 4, it is seen that despite the changes in pulp density, flotation yield did not change. For sample 7 percent values of the elements in concentrated phase are given in Table 5. Table 5 shows that percent values of the elements increased by 12 times, compared to the original sample.

As seen from the results above, the transportation of matters to concentrated phase takes 40 minutes. To reduce this duration, potassium amylxanthate was used instead of potassium isobutylxanthate. The transportation time with potassium amylxanthate was found to be 5 minutes and the results are given in Table 6 .

Table 6- Flotation of Sulfurized Asphaltite Ash with Potassium Amylxanthate*

\begin{tabular}{|c|c|c|c|c|c|c|c|}
\hline \multirow{2}{*}{$\begin{array}{l}\text { Floated } \\
\text { Material }\end{array}$} & \multicolumn{7}{|c|}{ Flotation yield of elements (\%) } \\
\cline { 2 - 8 } & $\mathbf{M o}$ & $\mathbf{V}$ & $\mathbf{U}$ & $\mathbf{N i}$ & $\mathbf{T i}$ & $\mathbf{F e}$ & $\mathbf{A l}$ \\
\hline Concentred & 100.0 & 100.0 & 100.0 & 99.8 & 100.0 & 97.7 & 5.5 \\
\hline Non-floated & - & - & - & 0.3 & - & 1.7 & 94.6 \\
\hline
\end{tabular}

As seen in Table 6, the flotation time became shorter ( 5 minutes), but there were no variations in flotation yields and collection of sample in concentrated phase. The main points regarding the floatability of $\mathrm{Mo}, \mathrm{U}, \mathrm{V}, \mathrm{Ni}$ and $\mathrm{Ti}$ in the asphaltite ash can be listed as follows: 
(i)Elements such as Mo, U, V, Ni and Ti in the asphaltite ash form complex compounds with main components such as silica, limestone and other metal oxides of ash. It is impossible to separate the elements above from main components of ash by direct flotation of original ash due to homogenous dispersion of these compounds.

(ii) A concentrability method such as flotation involves separating the elements mentioned above from asphaltite ash because the recovery of the elements are not economical by hydrometallurgical methods.

(iii) The aim of the developed method is, as stated above, to enable a floatable surface to form. Formation of this surface was considered to occur in solid-gas medium, thus, process was maintained under $\mathrm{H}_{2} \mathrm{~S}+\mathrm{H}_{2} \mathrm{O}$ vapor medium.

(iv) Flotation of sulfurized sample carried out after these processes proved that these elements were separated from main components and gave different compounds.

$$
\begin{aligned}
& \mathrm{CaUO}_{4}+3 \mathrm{H}_{2} \mathrm{~S} \rightleftarrows \mathrm{Ca}(\mathrm{OH})_{2}+\mathrm{US}_{3}+2 \mathrm{H}_{2} \mathrm{O} \\
& \mathrm{CaMoO}_{4}+3 \mathrm{H}_{2} \mathrm{~S} \rightleftarrows \mathrm{Ca}(\mathrm{OH})_{2}+\mathrm{MoS}_{3}+2 \mathrm{H}_{2} \mathrm{O} \\
& \mathrm{Ca}\left(\mathrm{VO}_{3}\right)_{2}+5 \mathrm{H}_{2} \mathrm{~S} \rightleftarrows \mathrm{Ca}(\mathrm{OH})_{2}+\mathrm{V}_{2} \mathrm{~S}_{5}+4 \mathrm{H}_{2} \mathrm{O} \\
& \mathrm{FeTiO}_{3}+\mathrm{H}_{2} \mathrm{~S} \rightleftarrows \mathrm{FeS}+\mathrm{TiO}_{2}+\mathrm{H}_{2} \mathrm{O} \\
& \mathrm{FeNi}_{2} \mathrm{O}_{4}+4 \mathrm{H}_{2} \mathrm{~S} \rightleftarrows \mathrm{FeS}+2 \mathrm{NiS}^{2}+4 \mathrm{H}_{2} \mathrm{O}+\mathrm{S} \\
& \mathrm{Ni}_{2} \mathrm{O}_{3}+3 \mathrm{H}_{2} \mathrm{~S} \rightleftarrows 2 \mathrm{NiS}+3 \mathrm{H}_{2} \mathrm{O}+\mathrm{S} \\
& \mathrm{Fe}_{2} \mathrm{O}_{3}+3 \mathrm{H}_{2} \mathrm{~S} \rightleftarrows 2 \mathrm{FeS}+3 \mathrm{H}_{2} \mathrm{O}+\mathrm{S}
\end{aligned}
$$

Mo, U, V, Ni and Ti form free sulphides and oxides as the reactions tend to the right slightly. These compounds are floated with anionic collectors such as xanthates, where their surface become positive at suitable $\mathrm{pH}$. Therefore, higher yields of flotation could be carried out as the written reactions were shifted to right. When this yield is obtained, the amount of matter collected in the concentrated phase becomes less. In this way, concentrates containing high percentage of Mo, U, V, Ni, Fe and Ti can be obtained. These were achieved by sulfurization under the seventh experimental condition in Figure 5.

(v) Optimum flotation conditions are given below:

Collector: (Z5) potassium amylxhantate $(0.2 \mathrm{~g} / \mathrm{L})$

Frother: Aeroflat $65(0.2 \mathrm{~mL}, 1 \%)$

pH: 6.5

Particle dimension: -200 mesh

Pulp density: $250 \mathrm{~g} / \mathrm{l}$

Stirring rate : $900 \mathrm{rpm}$.

Time of flotation: $5 \mathrm{~min}$.

(vi) The most suitable enrichment process was obtained for concentrate, flotation yield and percent of elements in concentrate under conditions stated above. 


\section{CONCLUSIONS}

By searching through the literature, it was found that ash samples such as coal ash, asphaltite ash, etc.. have very low direct flotation yields. In the present study, it was confirmed that using asphaltite ash in the flotation process does not promote the flotation of $\mathrm{Mo}, \mathrm{U}, \mathrm{V}, \mathrm{Ni}, \mathrm{Fe}$ and $\mathrm{Ti}$. Thus, in order to promote flotation, this new sulfurization method was developed by the authors. To obtain the best results, the structure and the surface should be suitable for flotation. For the sulfurization process, the ratio of $\mathrm{H}_{2} \mathrm{~S}$ and $\mathrm{H}_{2} \mathrm{O}$ is very important. This is one of the most important stages before the flotation. In the flotation of different samples of asphaltic ashes containing various amounts of metals, the sulfurization process, the flotation yield can be maximized [14$15]$.

\section{Acknowledgment}

Authors are grateful to Dicle University for financing this study [Project No: DUAP-99-EF-378]. The authors also wish to thank anonymous reviewers for their valuable comments.

\section{References}

1 Fuerstenau, D.W., Froth Flotation, The American Institue of Mining, Metallurgical, and Petroleum Engineers, (1962).

2 Zimmerman, R.E., Froth Flotation in Coal Preparation, Part $10,4^{\text {th }}$ Ed., J.W. Leonard,Ed., The American Institue of Mining, Metallurgical, and Petroleum Engineers, Inc., New York, 75-105 (1979).

3 Fuerstenau, D.W. and Pradip, Adsorption of Frothers at Coal/Water Interfaces, Colloids and Surfaces, 4, 229-243 (1982).

4 Fuerstenau, D.W., Rosenbaum, J.M., Laskowski, J., Effect of Surface Functional Groups on the Flotation of Coal, Colloids and Surfaces, 8, 153-174 (1983).

5 Harris, G.H., Jia, R., An improved class of flotation frothers, Int.J.Miner.Process.58, 35-43 (2000).

6 Edwards, C.R., Uranium Extraction Process alternatives, Mineral Processing, CIM Bulletin, March,958 (85), 118(1992).

7 Rao, K.A., Natarajan, R., Padmanabhan, N. P. H., Studies on recovery of copper, nickel, cobalt and molybdenum values from a bulk sulphide concentrate of an Indian uranium ore, Hydrometallurgy, 62,115-124 (2001).

8 Cebeci, Y., The investigation of the floatability improvement of Yozgat Ayridam lignite using various collectors, Fuel, ,81,(3), 281-289 (2002).

9 Malhotra D.; Hoover R.M.; Bender F.N., Effect of agitation on flotation of molybdenite, Mining Engineering (Littleton,Colorado) 32 ( 9), 1392-1397 (1980).

10 Wie J.M.; Fuerstenau D.W., Effect of dextrin on surface properties and the flotation of molybdenite, Int.J.Miner. Process.,1( 1), 17-32 (1974). 
11 Muthuswami S.V.; Vijayan S.; Woods D.R., Banerjee, S., Flotation of uranium from uranium ores in Canada. Part I-Flotation results with Elliot Lake Uranium ores using chelating agents as collectors, Canadian Journal of Chemical Engineering, 61(5), 728-744 (1983).

12 Muthuswami S.V.; Vijayan S.; Woods D.R., Flotation of uranium from uranium ores in Canada. Part II-Cupferron adsorption on uranium oxide, quartz, illite and a uranium ore from Elliot Lake, Canadian Journal of Chemical Engineering, 63,(4),650-661 (1985).

13 Yoshifumi,K.,Hiroaki;T.,Katsunori,M.,Kimiho,Y., Studies of collectors V the preparation of amidoxime type surfactants and the flotation of a trace amount of uranium, Bulletin of the Chemical Society of Japan, 56, (11), 3364-3369 (1983).

14 Akgün,A., Recovery of precious elements from fluorite ore, October 2002, pHD Thesis, Dicle University, Diyarbakır-TURKEY.

15 Aydin,F., Investigation of evaluation in the pyrite and oxidize copper ore, October 2002, pHD Thesis, Dicle University, Diyarbakır-TURKEY. 